\title{
Avaliação dos Modelos de Governança da Cadeia da Indústria Fonográfica Pré e Pós-Internet
}

\author{
Thiago Lobão de Almeida \\ Mestrando em Engenharia de Produção \\ pela USP, Thiago Lobão de Almeida \\ possui linha de pesquisa direcionada \\ para a análise de inovações em redes \\ produtivas, com estudo direcionado \\ para a avaliação dos impactos da \\ Internet na indústria da Música. \\ Curriculum Lattes: http://lattes.cnpq. \\ br/4307835750570774
}

\section{Davi Noboru Nakano}

Professor Doutor da Universidade de São Paulo, na Escola de Engenharia de Produção (PRO/EPUSP). Atua principalmente nos seguintes temas: Gestão do conhecimento e Indústrias Criativas.

Curriculum Lattes: http://lattes.cnpq. br/4547011512696906
Resumo: Este artigo pretende discorrer sobre as recentes alterações na dinâmica de governança da cadeia de produção da indústria fonográfica, propiciadas prioritariamente pelo surgimento de meios digitais de distribuição de conteúdo via Internet. Para cada momento histórico, são propostos modelos que facilitem a compreensão da dinâmica de governança entre os agentes da cadeia em estudo. Pode-se avaliar, desta forma, como a relação entre autores, gravadoras e consumidores se alterou com o surgimento das redes de compartilhamento de conteúdo na Web. O trabalho conclui sobre o movimento de redução da assimetria entre agentes na cadeia, para um modelo híbrido que tende ao formato de governança de mercado. No entanto, este novo cenário de governança não necessariamente adota a entidade preço como delineadora de oferta e demanda, sendo esta substituída por uma série de fatores de caráter mais intangível, como confiabilidade sobre a plataforma de acesso e controle do conteúdo musical por parte dos consumidores.

Palavras-chave: Indústria Fonográfica, Cadeias de Valor, Redes Produtivas, Modelos de Governança.

\begin{abstract}
This paper discusses how the governance of the phonographic industry has changed over time, and how the emergence of the digital distribution triggered the latest changes. To portrait the evolution of the industry, different governance models are proposed for each period, which characterize the relarionship between authors, artists, recording companies and consumers. This discussion concludes that the Internet and digital distribution has reduced the power assymetry in the industry, and price is not the main driver that defines consumer behavior: intangibles as image and trust on the technological platform, and the sense of control over content consumers can develop are important drivers.
\end{abstract}

\section{Introdução}

A música não é só uma manifestação artística, mas também um produto que movimenta um mercado de grande complexidade e importância, tanto social quanto econômica. O mercado musical, existente desde o final do século XIX, consolidou-se a partir da difusão do rádio (na década de 40) e, a partir daí, começou a conquistar espaço significativo no contexto econômico. As indústrias de cultura fortaleceram-se, conciliando a produção criativa intangível à produção industrial tradicional. Com o tempo, surgiram grandes gravadoras, multinacionais que dominaram a produção e distribuição de fonogramas, que são conhecidas como majors (PETERSON \& BERGER, 1975), hoje ligadas a grandes conglomerados de entretenimento, que, de fato, compreendem a maior parte dos negócios vinculados às etapas de concepção, produção e distribuição de fonogramas. 
Essas empresas, até a década de 1960, caracterizavam-se pela integração vertical desde processo produtivo até o processo de distribuição e divulgação (LOPES, 1992). Esta verticalização e, fundamentalmente, o controle sobre a difícil tarefa de distribuição física de conteúdo, garantiam às gravadoras o poder de barganha nos acordos sobre regime de apropriação de direitos autorais, tanto a partir dos direitos autorais conexos quanto de contratos exclusivos com os autores ou intérpretes (VOGEL, 2004).

O grau de investimento necessário para a circulação de conteúdo musical, seja nas vendas de mídias físicas, seja na inclusão do conteúdo nos meios radiofônicos, era uma grande barreira para a expansão dos ditos artistas "autônomos" ou "independentes", aqueles que, em geral por questões de concepção artística, não se associavam aos grandes players de mercado. Dessa forma, a entrada de um artista no portfólio de uma gravadora major resumia-se como única opção para evolução de sua carreira artística. O modelo de negócio variava pouco entre as gravadoras e assemelhava-se muito aos modelos de negócio de indústrias tradicionais de manufatura, mesmo com um produto de conteúdo essencialmente não-material.

Pode-se afirmar que toda a dinâmica de produção do conteúdo musical, desde a composição até a circulação na massa consumidora, ficava atrelada à tomada de decisão das gravadoras majors. Estas detinham o controle sobre o que seria vinculado à demanda e filtravam as diversas opções de artistas, num modelo instintivo de gestão de portfólio que contemplava, como principais fatores, a análise estética e de risco $\mathrm{X}$ retorno. Os compositores e artistas intérpretes se comportavam apenas como fornecedores cativos em uma indústria com grandes players verticalizados em produção e distribuição do conteúdo musical. A longevidade do ciclo profissional de um artista dependia, antes de tudo, de sua capacidade em se adequar aos padrões estéticos e financeiros idealizados pelas gravadoras.

Entretanto, a introdução da Internet ao contexto musical afetou a cadeia integrada de produção e divulgação. Em primeiro lugar, pela queda de barreiras tecnológicas, que possibilitaram uma produção amadora de boa qualidade (gradativo processo de minituarização dos equipamentos para gravações com fita magnética, no início da década de 80). Desse modo, os artistas passaram a não mais se submeter ao regime de apropriação antigo, realizando produções independentes mais lucrativas e, na visão de muitos, com distribuição de resultados mais justa. Em segundo lugar, a Internet permitiu a diversificação dos meios de distribuição a partir da criação da primeira rede P2P (o Napster, em 2000, rede de compartilhamento de conteúdo diretamente entre usuários em uma plataforma online - peer to peer). Isto tornou a divulgação artística livre, alheia ao controle antes exercido pelas grandes gravadoras. Surgiram, consequentemente, diversos modelos de distribuição baseados na aparente ausência de custos marginais relacionados à disponibilização virtual de conteúdo.

A facilitação da produção e, agora, também da circulação de conteúdo, incitava, na visão das gravadoras, a formação de um novo modelo de governança na cadeia fonográfica. Os grandes players não poderiam mais ter para si a garantia de governança sobre a cadeia e num primeiro momento, não poderiam prever o grau e a velocidade da suposta substituição das vendas de mídias físicas pelo consumo digital.

Com isto em vista, pode-se prever uma transição na dinâmica de governança da cadeia fonográfica. É nesta previsão que este artigo busca contribuir. Para tanto, são apresentados modelos de governança propostos por Gereffi et al (2005), com forte validação da comunidade acadêmica, que auxiliam na representação das relações entre empresas dentro de uma cadeia de valor. 
Primeiramente, apresenta-se um detalhamento sobre a dinâmica da cadeia fonográfica, desde a criação até a circulação de conteúdo. Esta apresentação já contempla as alterações estimuladas pelo consumo de fonogramas virtuais. Depois disso, são apresentados os diferentes modelos de governança de Gereffi et al (2005) fundamentando o embasamento teórico do autor para configuração destes. A seguir, a cadeia produtiva da indústria em estudo é analisada antes e depois da Internet, alocando os dois momentos históricos nas representações propostas. Por fim, conclui-se sobre qual deve ser a nova dinâmica da cadeia, cujo controle atual está descentralizado entre as gravadoras e os próprios artistas, que desempenham o papel de trabalhadores autônomos, auto-gerindo suas carreiras e utilizando os meios de produção, distribuição e divulgação de fonogramas como prestadores de serviços. Reduz-se, assim, a antiga assimetria de poder entre os diferentes agentes, num modelo de governança de mercado que, no entanto, não se orienta necessariamente pelo fator preço.

\section{Cadeia produtiva de música "pré-Internet"}

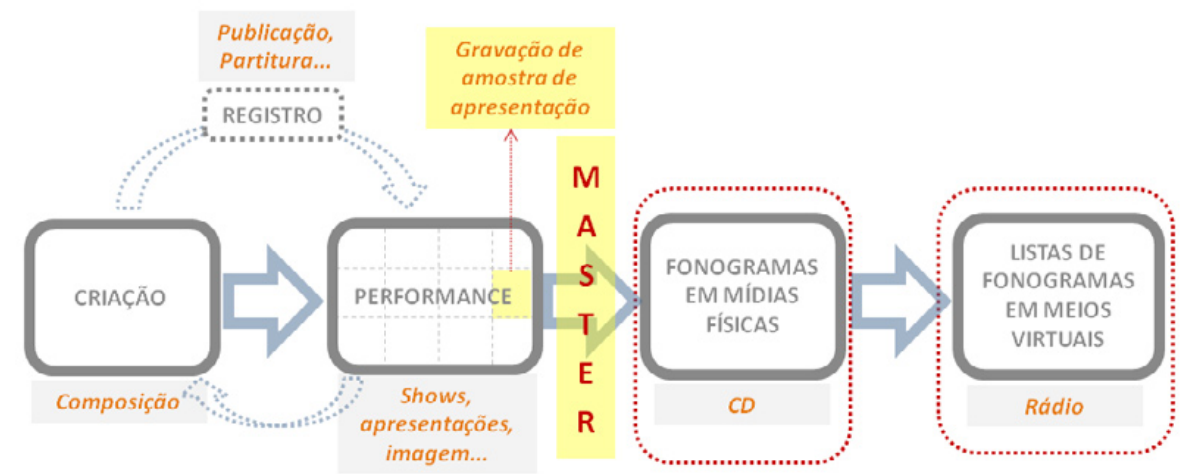

Figura 1 - Cadeia produtiva indústria fonográfica pré-Internet (Esquematização do autor)

A primeira etapa da cadeia compreende a criação e o desenvolvimento da composição desde sua base até a fase final, segundo a linguagem musical, incrementada por arranjos com a interação de instrumentos diversos. Nesta seara, surge a necessidade de órgãos reguladores das trocas de valores entre os diferentes participantes do processo de criação e execução de canções.

Um segundo elo da cadeia diz respeito à indústria de apresentações é a parte da cadeia da música mais filiada aos serviços, em diversos âmbitos, compreendendo exposições musicais cotidianas e encontros artísticos; eventos em casas de shows de médio porte até grandes festivais musicais. A elaboração de apresentações alavanca uma nova classe de organizações, as empresas promotoras de eventos, que garantem a infraestrutura necessária para a realização de eventos de maior porte.

Geralmente, fazem-se necessárias sucessivas repetições de uma mesma amostra da apresentação artística, para que enfim se possa partir para o processo de manufatura de cópias. Tecnicamente, o processo de produção da mídia master pode ser dividido em quatro etapas: Pré-produção, Produção, Mixagem e Masterização (VICENTE, 1996). São estas as atividades que definem a "indústria fonográfica" dentro da cadeia de produção de música.

A indústria fonográfica teve início na última década do século XIX, na qual três companhias de porte grande para os padrões da época (Victor, Columbia e Edison) detinham o controle de um mercado de oferta e demanda por cilindros de laca, as primeiras mídias físicas para fonogramas (ALEXANDER, 1994). Do cilindro de laca, desenvolveu-se o disco de laca, e consecutivamente, os discos de vinil primeiramente para gramofone e depois vitrolas, passando pelas fitas magnéticas, até os discos compactos atuais. 
Por mais que alguns destes casos se portassem como inovações exógenas à indústria e, dessa forma, instigassem a princípio uma natural rejeição dos grandes players pela troca de tecnologia, nenhum destes formatos físicos agrediu o oligopólio das majors, pelo contrário, acabaram por exaltar a alta concentração da indústria. As gravadoras gradativamente assumiram o destaque na cadeia produtiva, verticalizando a produção, mixagem e masterização, por meio de estúdios próprios ou atuando como hub logístico de rede de estúdios terceiros, integrando produção e distribuição. Naturalmente, estas empresas acabaram impondo para si significativas vantagens na apropriação de direitos e, portanto, na otimização de receitas, também se valendo da capacidade de seleção do que de fato seria vinculado à massa consumidora.

\section{Cadeia produtiva da música - "pós-Internet"}

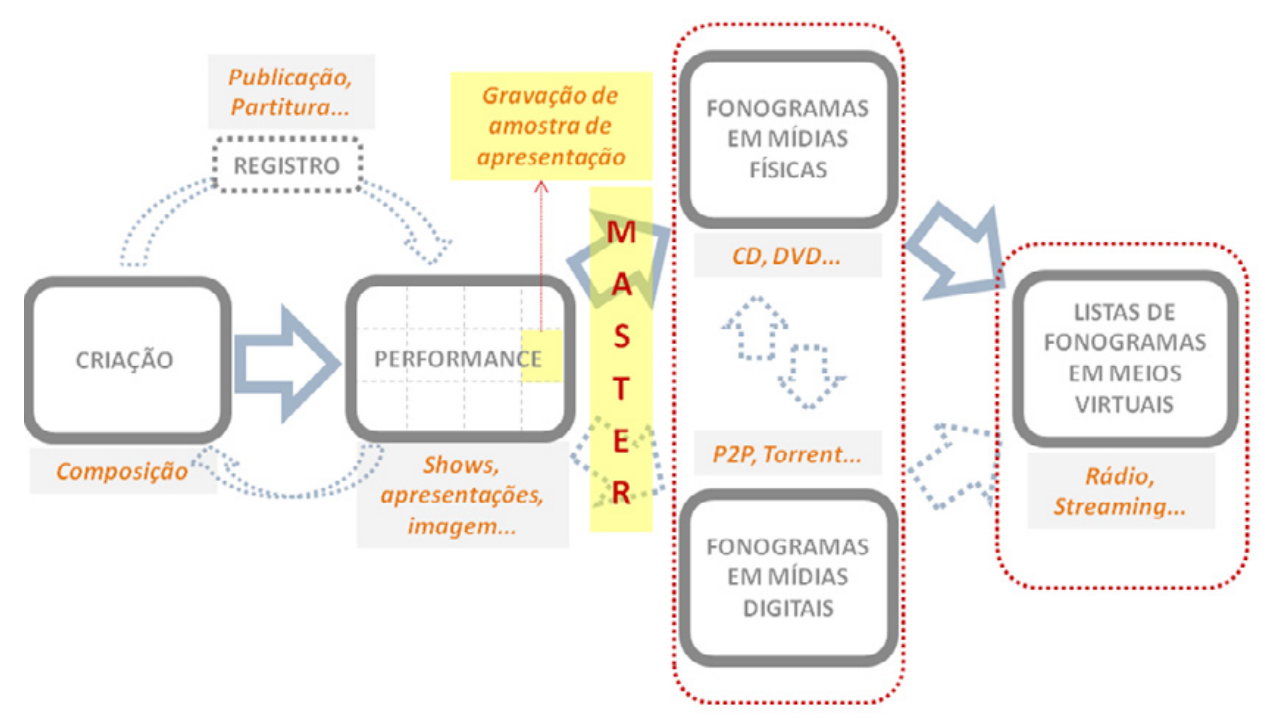

Figura 2 - Cadeia produtiva indústria fonográfica pós-Internet (Esquematização do autor)

As gravadoras se depararam com uma inovação de origem exógena, não somente à própria indústria fonográfica, mas também às indústrias do conteúdo como um todo: a Internet e, principalmente, o MP3, formato de compressão de áudio idealizado por engenheiros alemães da companhia Fraunhofer Gesellshaft (ALEXANDER, 2002). Gradativamente, os cinco grandes conglomerados multinacionais de entretenimento (Time Warner, BMG, EMI, Sony, Universal) começaram a observar uma queda relativamente abrupta das vendas de discos compactos no início do século XXI, vinculando tal fato ao consumo ilegal de reproduções de fonogramas compartilhadas por usuários em ambientes online. Iniciava-se uma guerra contra as plataformas P2P (peer-to-peer), das quais o website Napster foi o percussor.

A princípio, a reação das companhias focou a criação de modelos de negócio que competissem com os P2P (DUBOSSON-TORBAY ET AL, 2004), sem boas respostas de mercado. Primeiramente, o Napster, sistema de compartilhamento de arquivos em torno de um hub virtual centralizador, prevaleceu como design dominante na distribuição de mídias digitais. Depois, o Kazaa, sistema P2P baseado na descentralização das ações de compartilhamento (emissor do arquivo contata receptor sem a necessidade de um agregador de conteúdo). Mais recentemente, os sistemas Torrent também ganharam destaque e vêm ameaçando também outras indústrias de conteúdo, como a cinematográfica (CURRAH, 2006). O sistema permite uma maior velocidade de aquisição de arquivos, já que este permite downloads com fontes de arquivos descentralizadas ao invés de compartilhamento entre apenas dois usuários (CHOI \& PEREZ, 2007). 
Nesta seara, foram formuladas na literatura duas principais teorias em relação à coexistência entre as mídias físicas e virtuais (LIEBOWITZ, 2005). A teoria da substituição defende a ideia de que as mídias virtuais, principalmente por promoverem o aumento do bem-estar dos consumidores (comodidade e instantaneidade na obtenção dos arquivos), tenderão a substituir todas as mídias físicas com a expansão e desenvolvimento tecnológico da Internet. A expansão do alcance das tecnologias de banda larga, que aumentam a velocidade de download dos arquivos, maximizará os efeitos esperados. Por outro lado, a teoria da amostra defende a ideia de que, na realidade, a distribuição virtual facilitará o contato, por parte dos consumidores em geral, com uma maior gama de fonogramas distintos e, assim, as mídias virtuais podem não substituir as mídias físicas, mas sim complementar e impulsionar as vendas tradicionais.

A facilitação do processo de registro físico de conteúdo por parte dos próprios usuários impulsionou o fluxo de fonogramas entre os dois distintos meios de distribuição: físico e digital. No que diz respeito à transformação de mídias originariamente digitais em mídias físicas, duas consequências mercadológicas devem ser citadas: o aquecimento do mercado de venda de mídias físicas virgens, ou seja, sem conteúdo; e o reaquecimento da pirataria (SUNDARAJAN , 2004). No lado da demanda, também afloram fatores que beneficiam o consumo de mídias virgens: a evolução de hardware dos microcomputadores, que atualmente possuem sistemas de som de alta qualidade; a evolução de software destes, hoje capazes de imprimir conteúdo em discos compactos bastante rapidamente; a capacidade de compressão de arquivos em MP3 e, por fim, a facilidade de obtenção destes arquivos com conexão web em banda larga (BAKKER, 2005).

\section{Modelos de Governança}

Um vasto grupo de autores, em diversos ramos do conhecimento, se dispõe a tratar o tema de governança em cadeias de valor. Naturalmente, a diversificação dos movimentos de produção e comércio incitou o surgimento de uma variedade de formas de governança, trafegando, por um lado, entre redes de mercados em plena concorrência, por outro, entre grandes corporações verticalmente integradas.

Para se compreender variações de governança, portanto, faz-se necessário compreender a dinâmica de cadeias de valor. Williamson (1985) discute sobre indicadores que possam facilitar a compreensão da interação entre agentes neste novo modelo de produção e consumo, que de fato vai além do conceito tradicional de cadeia produtiva. Ao contrário do que pode se pensar, todavia, reconhecer a importância dos custos de transação numa estrutura de produção não precisa necessariamente induzir à conclusão de que sistemas de produção complexos e bem coordenados sempre resultam em integração vertical.

Nesta seara, Gereffi et al (2005) constroem um quadro teórico para ajudar a explicar os padrões de governança em cadeias globais de valor. Para tanto, buscam identificar variáveis que desempenhem um grande papel na determinação de como as cadeias de valor globais são governadas e, em especial, como se dá a transição da dinâmica de governança em um dado momento histórico. Os três parâmetros definidos são:

- Complexidade das transações, isto é, a dificuldade de transferência de informações necessárias para e realizar uma transação particular, relacionada a especificações de produto e/ou processo;

- Capacidade de codificar as transações, isto é, a medida em que as informações podem ser tratadas de forma a garantir uma transmissão eficiente de conhecimento, sem a necessidade de investimentos específicos para transação entre as partes de troca; 
- Capacidade da base de fornecedores, isto é, as condições dos potenciais e atuais fornecedores para cumprir com facilidade os requisitos de entrega dos recursos transacionados.

A teoria gera cinco tipos de governança global da cadeia de valor - modelo hierárquico, cativo, relacional, modular, e de mercado - que vão de alto a baixo nível de coordenação explícita e assimetria de poder.

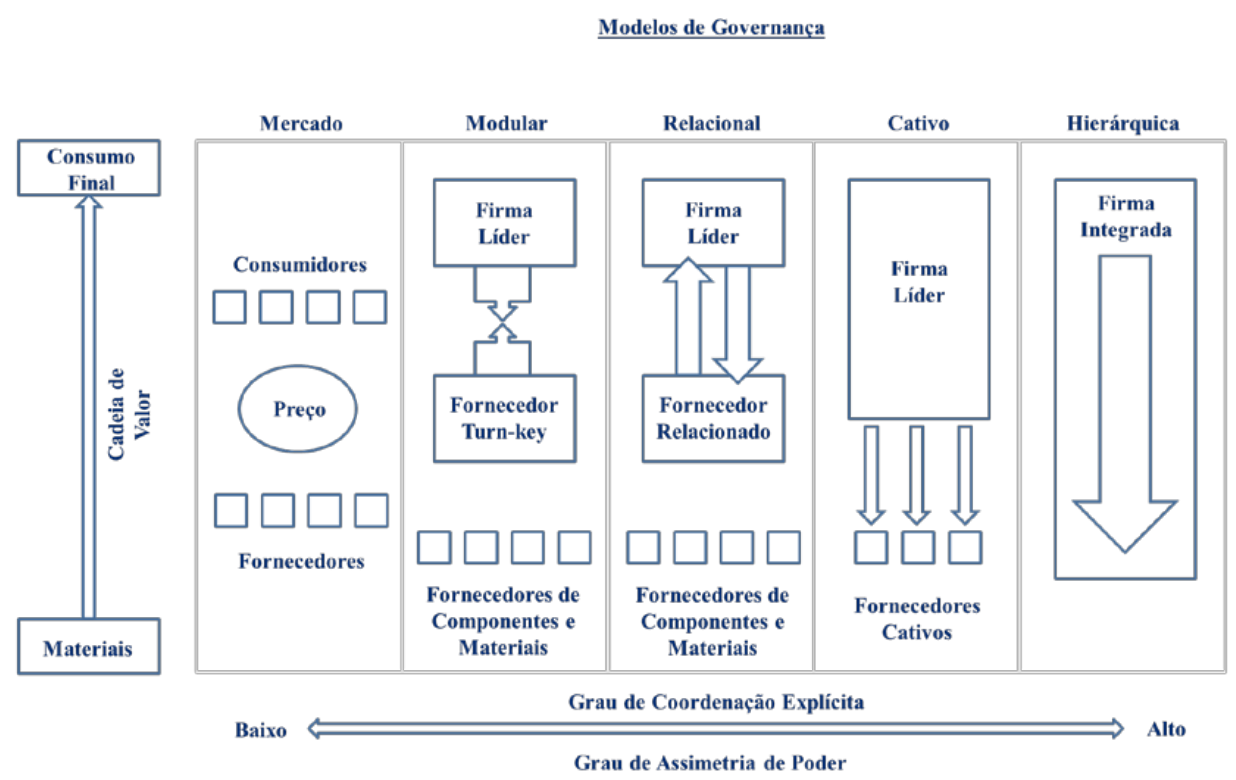

Figura 3 - Modelos de Governança em Cadeias de Valor - Representação de Gereffi et al (2005)

\begin{tabular}{lllll}
\hline Tipo de Governança & $\begin{array}{c}\text { Complexidade de } \\
\text { Transações }\end{array}$ & $\begin{array}{c}\text { Habilidade de } \\
\text { codificação das } \\
\text { transaçóes }\end{array}$ & $\begin{array}{c}\text { Capacidades da } \\
\text { base de } \\
\text { fornecedores }\end{array}$ & $\begin{array}{c}\text { Grau de } \\
\text { coordenação } \\
\text { explícita e } \\
\text { assimetria de } \\
\text { poder }\end{array}$ \\
\hline Mercado & Baixa & Alta & Alta & Mais Baixa \\
Modular & Alta & Alta & Alta & Baixa \\
Relacional & Alta & Baixa & Alta & Média \\
Hierárquica & Alta & Alta & Baixa & Alta \\
\hline
\end{tabular}

Fonte: Adaptado de Gereffi et al (2005)

Tabela 1 - Tipos de Governança

\section{Aplicação dos Modelos de Governança na Cadeia Fonográfica}

Tendo em vista o conjunto de modelos apresentados e, antes disso, a dinâmica relatada para a cadeia de produção da indústria fonográfica, pode-se enquadrar a indústria pré e pós-Internet nas representações esquematizadas por Gereffi et al (2005). Faz-se necessário analisar cada um dos momentos históricos sob a perspectiva dos parâmetros que orientam os modelos de governança estudados: i) complexidade das transações entre agentes, ii) capacidade de codificação destas transações e iii) capacidade da base de fornecedores.

A alta complexidade da distribuição física de fonogramas pré-Internet, a dificuldade em se codificar o processo de distribuição e a incapacidade dos artistas compositores em executar tal processo, caracterizam a cadeia de valor como típica de uma governança do modelo cativo, no qual as grandes gravadoras majors se comportam como empresas líderes. 


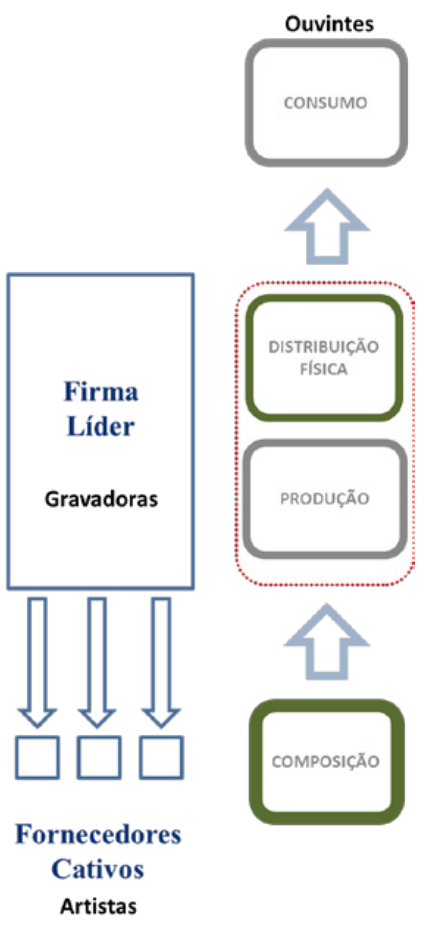

Figura 4 - Proposta de Modelo de Governança Cativo na Cadeia Fonográfica Pré-Internet

Os artistas, nesta lógica, são fornecedores cativos de um componente essencial para a produção de fonogramas: as composições musicais. De fato, na época préInternet as gravadoras trabalhavam na gestão de portfólios de artistas em seus selos, isto é, conjuntos de fornecedores cativos que, costumeiramente, tinham a função de enviar composições para a etapa de produção de fonogramas e, posteriormente, de distribuição física. Os artistas, portanto, tinham apenas a tarefa de geração das composições, extremamente dependentes das gravadoras líderes que exerciam as demais funções da cadeia de valor. As gravadoras, por sua vez, gerenciavam sua carteira de artistas compositores e intérpretes, observando a resposta de mercado e avaliando as competências de cada um. O modelo cativo de governança, em suma, delineava-se pelo planejamento estratégico das gravadoras na gestão de seus respectivos portfólios de artistas.

Na era pós-Internet, no entanto, uma série de fatores contribuiu para a alteração do padrão de governança. Primeiramente, o processo de produção de fonogramas a partir de composições foi simplificado por inovações tecnológicas dos equipamentos de gravação (gradativamente a partir dos anos 90), cada vez mais miniaturizados e baratos - iniciou-se a era de home studios, isto é, da gravação, mixagem e masterização de fonogramas de alta qualidade nas próprias residências de compositores. A produção de fonogramas, antes extremamente dispendiosa e vinculada à necessidade de alta competência técnica, passou a ser praticamente de livre acesso. 0 processo de registro fonográfico de composições deixou de ser peça fundamental para o domínio das gravadoras sobre seus portfólios de artistas. No entanto, neste primeiro instante de descontinuidade tecnológica, a relação de governança entre agentes da cadeia fonográfica permaneceu inalterada. De fato, a maior dificuldade dos artistas em vincular suas composições gravadas para o público ainda se dava na etapa de distribuição que, até aquele instante, ocorria única e exclusivamente por meio de mídias físicas.

Num segundo momento, com o advento da distribuição digital e, em especial, das plataformas virtuais para compartilhamento de dados, a barreira de distribuição autônoma de conteúdo musical passou a ser rompida. A gradativa evolução de desempenho dos meios de transmissão de dados e da usabilidade de portais de compartilhamento fez da internet um grande marketplace de conteúdo. Os músicos, portanto, passaram a enxergar a possibilidade de ganho de autonomia 
na cadeia fonográfica, não precisando mais se submeter às diretrizes estratégicas delineadas pelas majors. Surgia a possibilidade de autogerenciamento de carreiras artísticas, ou seja, um músico internauta passou a ser capaz de compor e, sem intermediários compulsórios, produzir e distribuir seu trabalho diretamente para um mercado online de consumidores.

As gravadoras, neste contexto passam, em boa parte dos casos, a se comportar como prestadoras de serviços para artistas, num modelo de governança que tende ao livre mercado - um grupo extenso de artistas, ou seja, de fornecedores de composições, mantém relações comerciais com uma série de empresas capazes de produzir seu conteúdo e, depois, distribuí-lo, seja fisicamente ou virtualmente. A relação entre artistas, produtores e distribuidores, torna-se de livre mercado, em geral, delineada pela entidade preço, assim como modelado por Gereffi et al (2005). Um compositor leva em consideração a capacidade e o custo envolvido para a escolha do produtor de seu conteúdo. A decisão por um distribuidor, analogamente, orienta-se pelos mesmos fatores.

No entanto, a relação entre fornecedores de conteúdo e consumidores na Web não necessariamente se dá pelo preço, já que a disponibilização de conteúdo em ambiente digital tem praticamente custo marginal nulo, o que, nas premissas microeconômicas, sugere preço zero para o produto ofertado. De fato, a gratuidade de fonogramas em plataformas P2P e streaming é uma realidade na indústria pós-Internet. Como já citado, a ausência de valor monetário incita uma série de discussões éticas e jurídicas principalmente a respeito da apropriação de direitos autorais. Novos modelos de negócio, todavia, precificando o conteúdo digital, também começam a emergir (como o iTunes). De qualquer forma, é evidente a ausência de uma entidade como o fator preço, na grande maioria dos casos de consumo, para orientar a dinâmica de comercialização entre distribuidores digitais e consumidores internautas. Um conjunto de fatores, em geral, atrelados à comodidade de aquisição e controle do conteúdo musical, substitui o fator preço na escolha da demanda entre as diversas fontes de disponibilização online de fonogramas.

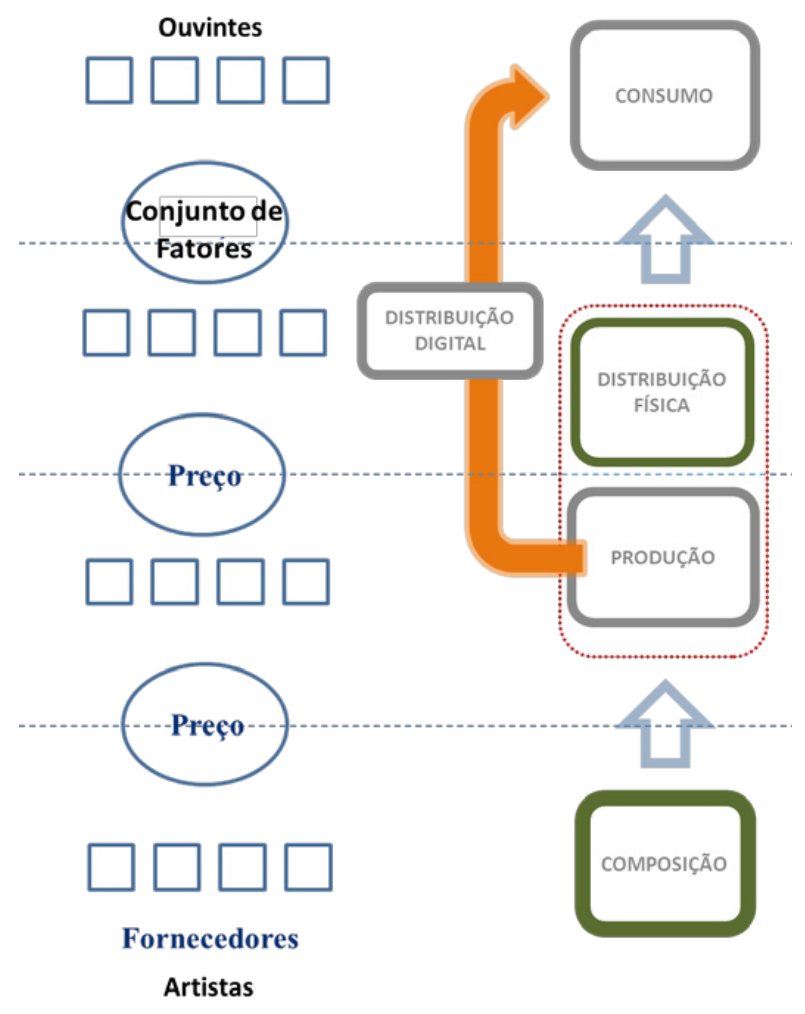

Figura 5 - Proposta de Modelo de Governança de Mercado (adaptado) na Cadeia Fonográfica Pós-Internet 


\section{Observações finais}

Visto a grande repercussão acadêmica a cerca da introdução da música aos meios digitais de distribuição, evidenciada pela numerosa quantidade de artigos sobre o tema, pode-se inferir a extrema importância da revolução externa atuante na cadeia da indústria fonográfica atual. O questionamento fundamental sobre a transição do modelo de governança na cadeia de valor da indústria fonográfica, tendo em base o acervo acadêmico consultado, em especial o trabalho de Gereffi et al (2005), forneceu um panorama robusto para as discussões apresentadas.

A evolução dos meios de produção, através da miniaturização e barateamento de equipamentos iniciou um processo de descentralização da governança na cadeia fonográfica, dando aos artistas a possibilidade de gerenciamento, ou seja, de tomada de decisão não somente na composição de conteúdo musical, mas também no processo de produção de fonogramas. Esta tendência de descentralização, no entanto, só se transformou em realidade concreta com o advento da Internet e, consequentemente, da possibilidade de distribuição digital de dados. Neste momento, composição, produção e também distribuição passaram a se tornar processos de menor complexidade e alta codificação, o que aumentou a capacidade da base de fornecedores de composições em acessar os consumidores finais do conteúdo musical, principalmente por meio da Web.

Em suma, após mais de uma década de consolidação da distribuição fonográfica digital, se verifica uma ação de convergência da governança da cadeia de valor desta indústria, saindo de um modelo de governança cativo para um modelo de livre mercado entre compositores, produtores, distribuidores e consumidores finais.

\section{Referências Bibliográficas}

ALEXANDER, P. J. Net Technology and Market Structure: Evidence from the Music Recording Industry. Journal of Cultural Economics. Volume 18, 1994, pp. 113123.

ALEXANDER, P. J. Peer-to-Peer File Sharing: The Case of the Music Recording Industry. Review of Industrial Organization. Volume 20, 2002, pp. 151-161.

BAKKER, P. File-sharing-fight, ignore or compete. Paid download services vs. P2Pnetworks. Telematics and Informatics. Volume 22, 2005, pp. 41-55.

BHATTACHARJEE, S., GOPAL, R., LERTWACHARA, K., MERSDEN, J. R. Whatever happened to payola? An empirical analysis of online music sharing. Decision Support Systems. Volume 42, 2006, pp. 104-120.

COURA, L. D. C. Pirataria e Novos Modelos de Negócio no Mercado Musical. Economia da Cultura e Extensão Universitária. São João Del Rei: Malta, 2010.

CURRAH, A. Hollywood versus the Internet: the media and entertainment industries in a digital and networked economy. Journal of Economic Geography. Volume 6, 2006, pp. 439-468.

DUBOSSON-TORBAY, M., PIGNEUR, Y., USUNIER, J-C. Business Models for Music Distribution after P2P Revolution. Proceedings of the Fourth International Conference on Web Delivering of Music. 2004.

DUCHÊNE, A. \& WAELBROECK, P. The legal and technological battle in the music industry: Information-push versus information-pull technologies. International Review of Law and Economics. Volume 26, 2006, pp. 565-580. 
GEREFFI, G. The organization of buyer - driven global commodity chains: How U.S. retailers shape overseas productions networks. In: GEREFFI, G. ; KORZENIEWICZ, M. Commodity chains and global capitalism. Westport: Praeger, 1994.

GEREFFI, G.; HUMPHREY,J.; STURGEON,T. The governance of global value chains, Review of International Political Economy 12:1 February 2005: 78-104.

HUMPHREY, J.; SCHMITZ, H., Governance and upgrading: linking industrial cluster and global value chain research, IDS Working Paper 120, Institute of Development Studies, University of Sussex, 2000.

LEYSHON, A. Time-space (and digital) compression: software formats, musical networks, and the reorganization of the music industry. Environmental and Planning. Volume 33, 2001, pp. 49-77.

LIEBOWITZ, S. J. File Sharing: Creative Destruction or Just Plain Destruction? Journal of Law and Economics. Volume 49, 2006.

LIEBOWITZ, S. J. Pitfalls in Measuring the Impact of File-sharing on the Sound Recording Market. CESifo Economic Studies. Volume 51, 2005, pp. 435-473.

MENEZES, D. P., LIMA, V. S., KAMEL, J. A. N., QUELHAS, O. L. G. É assim que a banda toca: modelagem da cadeia de valor da atividade de uma banda de música independente. XXVI ENEGEP. 2006.

NAKANO, D.N. Fluxos de conhecimento em redes interorganizacionais: conceitos e fatores de influência, in AMATO NETO, J. (org.) Redes entre organizações: Domínio do conhecimento e da eficácia operacional, Ed. Atlas, SP, 2005.

OBERHOLZER-GEE, F. \& STRUMPF, K. The Effect of File Sharing on Record Sales: An Empirical Analysis. Journal of Political Economy. Volume 115, Number 1, 2007.

PETERSON, R. A. \& BERGER, D. G. Cycles in Symbol Production: The Case of Popular Music. American Sociological Review. Volume 40, 1975, pp. 158-173.

SUNDARAJAN, A. Managing Digital Piracy: Pricing and Protection. Information Systems Research. Volume 15, Number 3, 2004, pp. 287-308.

VICENTE, E. A vez dos independentes (?): um olhar sobre a produção musical independente no país. Compós: Revista da Associação Nacional dos Programas de Pós-Graduação em Comunicação. 2006.

VICENTE, E. Organização, crescimento e crise: a indústria fonográfica brasileira nas décadas de 60 e 70 . Revista de Economía Política de las Tecnologías de la Información y Comunicación. Volume 8, Número 3, 2006, pp. 114-128.

VOGEL, H. L. Entertaiment Industry Economics Cambridge. UK: Cambridge University Press, 2004.

VOLZ, I. P. The Impact of Online Music Services on the Demand for Stars in the Music Industry. International World Wide Web Conference Committee. 2006, pp. 23-26.

WILLIAMSON, O. E. ,The economic institutions of capitalism - firms, markets, relational contracting. New York, The Free Press, 1985. 